\title{
B6 - RETRATAMENTO COM ALFAPEGINTERFERONA DA HEPATITE C GENÓTIPOS 2 E 3 EM UM SERVIÇO DO SUS
}

${ }^{2}$ Simara Artico; ${ }^{2}$ Karine Medeiros Amaral; ${ }^{2}$ Candice Beatriz Treter Gonçalves; ${ }^{1,2}$ Paulo Dornelles Picon

Instituições: ${ }^{1}$ Universidade Federal do Rio Grande do Sul, ${ }^{2}$ Centro de Monitorização de Medicamentos Injetáveis (CAMMI)-Hospital Sanatório Partenon

Objetivo: A hepatite Viral Crônica C tem sido reconhecida como um dos principais problemas em saúde pública, com grande impacto econômico e na qualidade de vida das populações. Estima-se que cerca de $3 \%$ da população mundial esteja cronicamente infectada por este agente viral. O vírus da hepatite $\mathrm{C}(\mathrm{HCV})$ constitui, atualmente, a principal causa de hepatite crônica e é uma importante causa de cirrose em todo mundo. Mais do que $50 \%$ dos pacientes infectados pelo HCV não respondem ao tratamento com interferon convencional (IFN) associado a ribavirina (RBV). O objetivo do nosso estudo foi avaliar a efetividade do retratamento com alfapeginterferona $2 \mathrm{a}$ ou $2 \mathrm{~b}$ (PEG-IFN 2a ou 2 b) concomitantemente com RBV, em pacientes com HCV, genótipo 2 e 3, que foram não-respondedores ou recidivantes ao primeiro tratamento convencional com IFN/RBV e identificar possíveis fatores preditivos de resposta virológica sustentada (RVS).

Metodologia: No período de setembro de 2003 a março de 2009 uma coorte de 216 pacientes portadores de hepatite $\mathrm{C}$ foram acompanhados em um serviço especializado, implementado no Sistema Único de Saúde-Rio Grande do Sul/Brasil. Todos os pacientes foram retratados com PEG-IFN 2a ou 2b, na dose de $180 \mathrm{mcg}$ ou 1,5 mcg/Kg de peso corporal por semana, respectivamente, associado a RBV na dose de $1.000-1.250 \mathrm{mg} / \mathrm{dia}$ por 48 semanas. O HCV-RNA foi testado por Polymerase Chain Reaction (PCR) nas semanas 12 (por PCR quantitativo), 48 e 72 (por PCR qualitativo). A resposta virológica (RV) nas 48 semanas e a RVS nas 72 semanas foram considerados para avaliação de eficácia do tratamento. As análises foram realizadas nos pacientes que receberam pelo menos 1 dose de PEG-IFN 2a ou $2 b$.

Resultados: A taxa de RVS para os pacientes não-respondedores ao primeiro tratamento foi de $34,4 \%$ e para os recidivantes foi de $50 \%(\mathrm{P}=0,031)$ através do teste exato de Fisher. Foram identificados como fatores preditivos que contribuem na melhora da RVS, a idade $(\mathrm{P}=0,005)$, ser recidivante ao tratamento anterior $(\mathrm{P}=0,023)$ e apresentar exame de biópsia 
hepática Metavir F0-F2 ( $\mathrm{P}=0,004)$, os demais fatores avaliados não demonstraram diferença estatística significativa. Na avaliação do perfil de segurança 51 pacientes $(23,6 \%)$ interromperam precocemente o tratamento. Destes, $18,5 \%$ por eventos adversos onde os mais frequientes foram anormalidades laboratoriais (40\%), óbito (20\%) e cirrose descompensada $(17,5 \%)$.

Conclusão: Este é o primeiro estudo pragmático realizado no cenário da realidade do SUS brasileiro que avalia a efetividade do retratamento com PEG-IFN 2a ou $2 \mathrm{~b}$ e RBV. Esta alternativa de retratamento para pacientes que falharam à terapias prévias anti-HCV, tem demonstrado uma promissora taxa de RVS, desde que seja feita uma seleção cuidadosa dos pacientes com fatores preditivos de resposta e monitorizados os eventos adversos. 